University of Wollongong

Research Online

Faculty of Engineering and Information

Faculty of Engineering and Information

Sciences - Papers: Part B

Sciences

2018

Experimental performance analysis and evaluation of a novel frost-free air source heat pump system

Zhihua Wang

Xi'an Jiaotong University, zhihua@uow.edu.au

Fenghao Wang

Xi'an Jiaotong University

Zhenjun $\mathrm{Ma}$

University of Wollongong, zhenjun@uow.edu.au

Mengjie Song

University of Tokyo

Wenke Fan

University of Wollongong,wf303@uowmail.edu.au

Follow this and additional works at: https://ro.uow.edu.au/eispapers1

Part of the Engineering Commons, and the Science and Technology Studies Commons

Research Online is the open access institutional repository for the University of Wollongong. For further information contact the UOW Library: research-pubs@uow.edu.au 


\title{
Experimental performance analysis and evaluation of a novel frost-free air source heat pump system
}

\begin{abstract}
To tackle the problem of frosting occurred on the outdoor coil surface when an air source heat pump (ASHP) is operated in winter, a novel frost-free ASHP system has been developed. However, the dehumidification performance and the frost-free time of the system operated are highly dependent on the electronic expansion valve (EEV) opening of the 1st stage throttle. In addition, the coefficient of performance (COP) of the systems is controlled by the EEV opening of the 2nd stage throttle. Therefore, the objective of this study is to investigate the effect of the EEV opening on the system thermodynamic performance in terms of dehumidification efficiency, regeneration efficiency, compression ratio, heating capacity and COP. It was observed that the optimal performance was achieved when the EEV openings of the 1 st stage throttle and 2 nd stage throttle were $75 \%$ and $40 \%$ respectively. In addition, a correlation of COP with the EEV openings of the 1st stage throttle and 2nd stage throttle was developed to optimize the system performance. The results showed that the system thermodynamic characteristics were highly sensitive to the variation in the EEV openings of both the1st stage throttle and 2nd stage throttle.
\end{abstract}

\section{Keywords}

evaluation, analysis, performance, experimental, heat, system, source, pump, air, frost-free, novel

\section{Disciplines}

Engineering | Science and Technology Studies

\section{Publication Details}

Wang, Z., Wang, F., Ma, Z., Song, M. \& Fan, W. (2018). Experimental performance analysis and evaluation of a novel frost-free air source heat pump system. Energy and Buildings, 175 69-77. 
Highlights

- A set of experiments for a novel frost-free ASHP system are performed.

- Effect of various EEV openings on the system performance is investigated.

- The optimal system COP is achieved under the test conditions.

- A correlation of the system COP with the EEV openings is obtained. 


\title{
Experimental performance analysis and evaluation of a novel frost-free air source heat pump system
}

\author{
ZhihuaWang $^{\text {a*, }}$ FenghaoWang ${ }^{\mathrm{a} *}$, Zhenjun $\mathrm{Ma}^{\mathrm{b}}$, Mengjie Song ${ }^{\mathrm{c}}$, Wenke Fan
}

${ }^{a}$ School of Human Settlements and Civil Engineering, Xi'an Jiaotong University, Xi'an, Shaanxi, 710049, China

${ }^{\mathrm{b}}$ Sustainable Buildings Research Centre (SBRC), Faculty of Engineering/and Information Sciences, University of Wollongong, Wollongong 2522, NSW, Australia

${ }^{c}$ Department of Human and Engineered Environmental Studies, Graduate School of Frontier Sciences, The University of Tokyo, Chiba, Japan

\begin{abstract}
To tackle the problem of frosting occurred on the outdoor coil surface when an air source heat pump (ASHP) is operated in winter, a novel frost-free ASHP system has been developed. However, the dehumidification performance and the frost-free time of the system operated are highly dependent on the electronic expansion valve (EEV) opening of the $1^{\text {st }}$ stage throttle. In addition, the coefficient of performance (COP) of the systems is controlled by the EEV opening of the $2^{\text {nd }}$ stage throttle. Therefore, the objective of this study is to investigate the effect of the EEV opening on the system thermodynamic performance in terms of dehumidification efficiency, regeneration efficiency, compression ratio, heating capacity and COP. It was observed that the optimal performance was achieved when the EEV openings of
\end{abstract}


the $1^{\text {st }}$ stage throttle and $2^{\text {nd }}$ stage throttle were $75 \%$ and $40 \%$ respectively. In addition, a correlation of COP with the EEV openings of the $1^{\text {st }}$ stage throttle and $2^{\text {nd }}$ stage throttle was developed to optimize the system performance. The results showed that the system thermodynamic characteristics were highly sensitive to the variation in the EEV openings of both the $1^{\text {st }}$ stage throttle and $2^{\text {nd }}$ stage throttle.

Keywords: Air source heat pump; EEV opening; Solid desiccant; Erost; Energy storage device

* Corresponding author. Tel:+86-13227006940; Fax:+86-29-83395100.

E-mail address: fhwang@mail.xjtu.edu.cn(Fenghao Wang);

wangzh065@xjtu.edu.cn(Zhihua Wang) 


\section{Nomenclature}

Q heating capacity, kW

T temperature, ${ }^{\circ} \mathrm{C}$

W compressor power consumption, $\mathrm{kW}$

m mass of water vapor, $g$

Greek letter

$\eta \quad$ efficiency, $\%$

Subscripts

ave average

de dehumidification

$\mathrm{hm} \quad$ heating mode

rm regeneration mode

re regeneration

wv water vapor

Abbreviations

ASHP air source heat pump

COP coefficient of performance

EHECSD extra heat exchanger coated with a solid desiccant

ESD energy storage device

EEV electronic expansion valve

PCM phase change material

$\mathrm{RH} \quad$ relatively humidity 


\section{Introduction}

In recent years, the energy and environment issues are increasingly rigorous, particularly in the field of building energy consumption that is responsible for over $30 \%$ of total energy in China[1][2]. It accounts for $63 \%$ of overall energy consumption in buildings for space heating and cooling [3]. In addition, environmental pollution is caused by the progressive depletion of fossil fuels. Therefore, promoting the deployment of renewable and clear energy, such as solar energy, air energy and wind energy, is essential to tackle this challenging problem. Air source heat pump (ASHP), as an energy conservation and environmental friendliness equipment, has been widely applied for heating and cooling in both domestic and commercial buildings [4][5]. However, when an ASHP unit is operated in winter, frost forms on the outdoor coil surfaces as the coil surface temperature may be lower than the freezing temperature, which will increase the thermal resistance and hinder the airflow through the evaporator. This will result in the decrease in the coefficient of performance (COP) and heating capacity by $35-60 \%$ and $30-57 \%$, respectively [6][7][8][9]. The frosting on outdoor coil has been identified to significantly impact the performance of ASHP units. Therefore, it is necessary to defrost these units periodically [10][11].

In order to improve the thermal behavior of ASHP systems and to get a better understanding of its characteristics with the purpose of promoting the usage through a wide variety of methods, a number of investigations have been conducted. Up till now, the reverse cycle defrosting, which switches heat pump from space heating to cooling using a four-way reversing valve, is the most widely used defrost method[12][13][14][15]. However, this method may result in a cold draft phenomenon due to the absorbed heat from indoor during 
the defrosting operation. Moreover, when the unit started to melt the frost, the suction and discharge pressure fluctuated suddenly, causing the mechanical damage to the compressor [16][17][18]. Some new defrosting methods, such as hot gas bypass defrosting method, thermal energy storage defrosting method [19][20] and retardation frost technology [21][22] [23], have been developed recently. Huang et al. [24] compared the thremal behaviors between the defrosting methods of the hot gas bypass defrosting and reverse cycle on an ASHP unit. It was found that the defrosting time of hot gas bypass defrosting was $272 \mathrm{~s}$, which was 2.89 times higher than that of the reverse cycle defrosting time of $94 \mathrm{~s}$ at the outdoor temperature of $2.0^{\circ} \mathrm{C}$ and relative humidity of $80 \%$. Kim et al. [25] developed a novel method which combined a dual hot gas bypass defrosting with an accumulator heater for an ASHP unit. The results showed that the novel method reduced $15 \%$ of the defrosting time in comparison to the reverse cycle defrosting method.

Development of defrosting methods is helpful to improve the performance of ASHP units. However, most methods cannot fundamentally solve the frosting problem on the outdoor heat exchanger. In addition, the mal-defrosting phenomenon always takes place in the actual operation that caused increased energy losses [26][27]. According to the long term field test by Zhu et al.[28] and Ge et al.[29] in Beijing, China, it was found that approximately 76.7 and $63 \%$ of defrosting operations were unnecessary. Wang et al.[30] reported the characteristics of an ASHP unit under two kinds of typical mal-defrost phenomenon. The first type was the defrosting process which took a long time after a "critical" level of frosting has been reached and the second type was the "unnecessary defrosting". The results indicated that the two phenomena led to the heating capacity decreased by 29 and $4.2 \%$ respectively. 
Therefore, it is challenging to achieve both energy savings and avoid frost accumulation on the outdoor coil.

Recently, extensive research efforts have been devoted to develop new methods to realize frost-free ASHP units and the working mechanism is to decrease the air moisture before the outdoor air passes through the evaporator by using liquid or solid desiccant dehumidification [31][32].J iang et al.[33] developed a solution spray subsystem to prevent the frost accumulation on the evaporator of an ASHP unit. Zhang et al. [34][35] proposed two frost-free ASHP units combined with liquid and solid desiccant dehumidifidation, respectively. The result indicated that the COP of the system combined with liquid dehumidification was 30 - $40 \%$ higher than that of the ASHP unit with electric humidifying system under the outdoor temperature of $-7^{\circ} \mathrm{C}$ to $5.5^{\circ} \mathrm{C}$ and relatively humidity $(\mathrm{RH})$ of $80 \%$. For the system with solid dehumidification, the COP was 5-30\% higher than that of hot gas bypass defrosting when the outdoor temperature was $-7-5.5^{\circ} \mathrm{C}$ and the RH was $60-80 \%$. Wang et al. [36][37] proposed a novel frost-free ASHP system integrated with solid desiccant and phase change materials (PCMs). The PCM was used to absorb part of the condensation heat in the heating mode and to regenerate the solid desiccant in the regeneration mode. Two EEVs were used to regulate the refrigerant flow to improve the system performance in the heating mode. The results indicated that the system COP was $17.9 \%$ and $3.4 \%$ higher than that of the reverse cycle defrosting method at the outdoor temperature of $-3^{\circ} \mathrm{C}$ and $3^{\circ} \mathrm{C}$, respectively.

For a heat pump system, the expansion device is one of the critical components to regulate refrigerant mass flow so as to maintain a superheated state before it flows into the compressor. It plays an important role in improving the heat pump system performance. In 
recent years, electronic expansion valve (EEV) has been widely applied in the heat pump unit because of a robust adaptability for different operating conditions. Peng et al.[38] compared the performance of an ASHP using EEV, capillary tube and short tube orifice as the expansion device. The results showed that the performance of the system using EEV throttling was the best among different options considered. Hou et al.[39] demonstrated that the EEV opening greatly impacted a transcritical $\mathrm{CO}_{2}$ refrigeration system performance, and the results indicated that the maximum system COP and cooling capacity were achieved when the EEV openings were $40 \%$ and $60 \%$, respectively.

For the novel frost-free ASHPWH system proposed by Wang et al.[36][37], the solid desiccant released the adsorption heat during the adsorption process, leading to the increased temperature of the solid desiccant and dehumidification performance degradation and further resulted in the descend in the frost-free operation time and the overall performance of the system. However, the dehumidification performance of the solid desiccant and the frost-free time of the system operated are highly dependent on the EEV opening of the $1^{\text {st }}$ stage throttle. In addition, the superheat degree and COP of such systems are controlled by the EEV opening of the $2^{\text {nd }}$ stage throttle. Therefore, in order to improve the system thermodynamic performance further, the aim of this paper is to investigate the effect of openings of the $1^{\text {st }}$ stage throttle and $2^{\text {nd }}$ stage throttle on the performance of the system with EEV as the throttle regulator in terms of the dehumidification efficiency, regeneration efficiency, compressor suction and discharge temperatures, compression ratio, heating capacity and COP. The working principle of the system is first presented, followed by the description of the experimental setup and experimental procedure. Lastly, the experimental results analysis and 
conclusions including its characteristic and performance are reported. Finding from this study are expected to assist in the optimal design of the studied system.

\section{Experimentation}

2.1Description of the novel system cycle

The detailed schematic of the studied system has been reported in the literature [37]. Therefore, a brief description is provided hereafter.

As shown in Fig. 1, the studied system consists of a compressor, a condenser which wraps around the outer wall of a water tank, three EEVs, an outdoor heat exchanger, an energy storage device (ESD), an extra heat exchanger coated with a solid desiccant (EHECSD), and four solenoid valves. The operation of the system include heating mode and regeneration mode, and details about the operation modes are presented as follows.

During the heating mode, first, the refrigerant is compressed by the compressor (1), then it enters the condenser (4) and ESD (6). After absorbing the condenser waste energy, it passes through the EHECSD (9) after the $1^{\text {st }}$ stage throttled (EEV 8) by EEV, and then passes through the outdoor heat exchanger (12) after the $2^{\text {nd }}$ stage throttled (EEV 11) by EEV. Lastly, the refrigerant returns to the compressor (1).

During the regeneration mode, the $\operatorname{EEVs}(8,11)$ are full open. The refrigerant is compressed by the compressor (1), then it first enters the condenser (4) and EHECSD (9), where the solid desiccant was heated, then it passes through the outdoor heat exchanger (12) and is throttled by EEV (17). Lastly, the refrigerant passes into ESD (6) and returns to the compressor (1). 


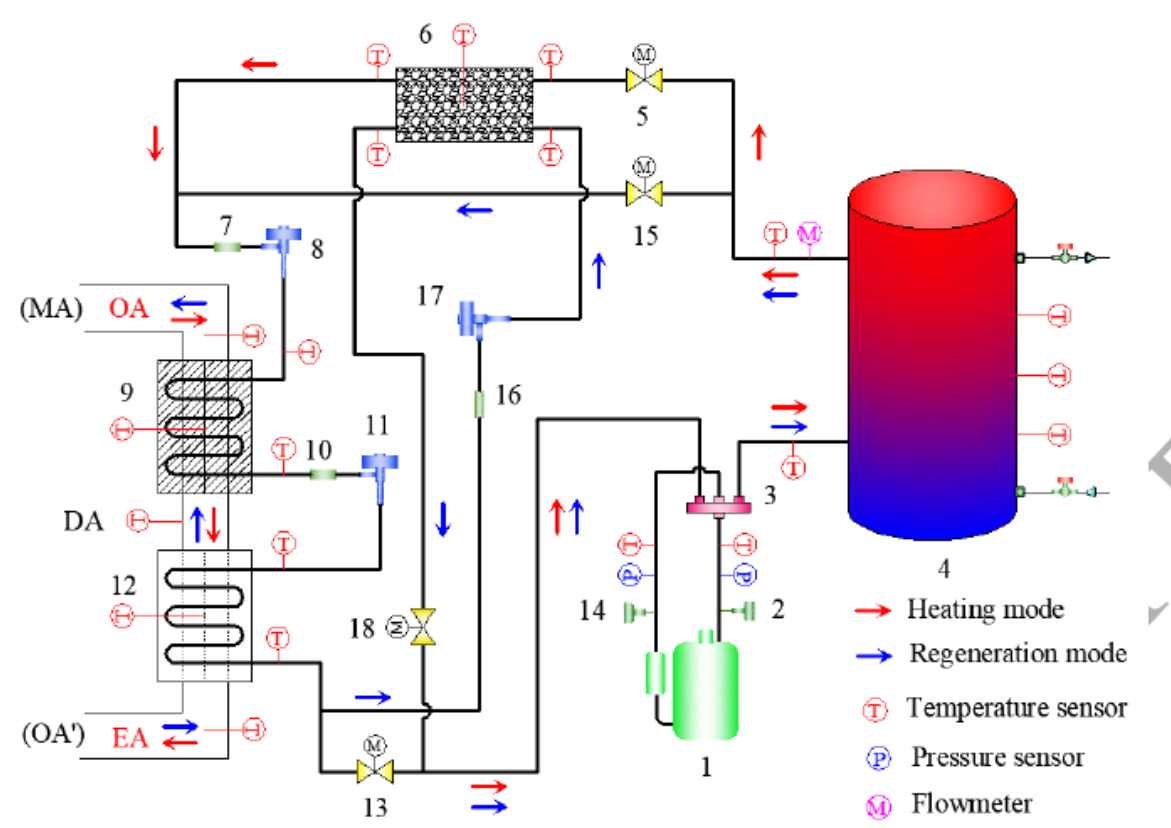

1-Compressor; 2/14-High/Low pressure protection device; 3-Four-way valve;

4-Water tank; 5,13,15,18-Solenoid valve; 6- Energy storage device;

7,10,16-Filter drier; 8,11,17-EEV; 9-HECSD; 12-Evaporator

Fig. 1 Schematic of the novel frost-free ASHP system.

\subsection{The frost-free ASHP experimental system}

An experimental setup for the novel frost-free ASHP system was built up, and it was performed in an air enthalpy type psychrometric room that was capable of simulating outdoor frosting environment. The dry-bulb temperature and $\mathrm{RH}$ of the room can be controlled with in the range of $-20-60^{\circ} \mathrm{C}$ and $30-92 \%$, respectively. The dimensions of room is $5.0 \times 5.0 \times 3.5$ m. Fig. 2 illustrates the photo of the experimental unit in the psychrometric room. Silica was employed for the solid desiccant and $\mathrm{CaCl}_{2} \bullet 6 \mathrm{H}_{2} \mathrm{O}$ was used for PCM. The detailed parameters of the system are listed in Table 1. 


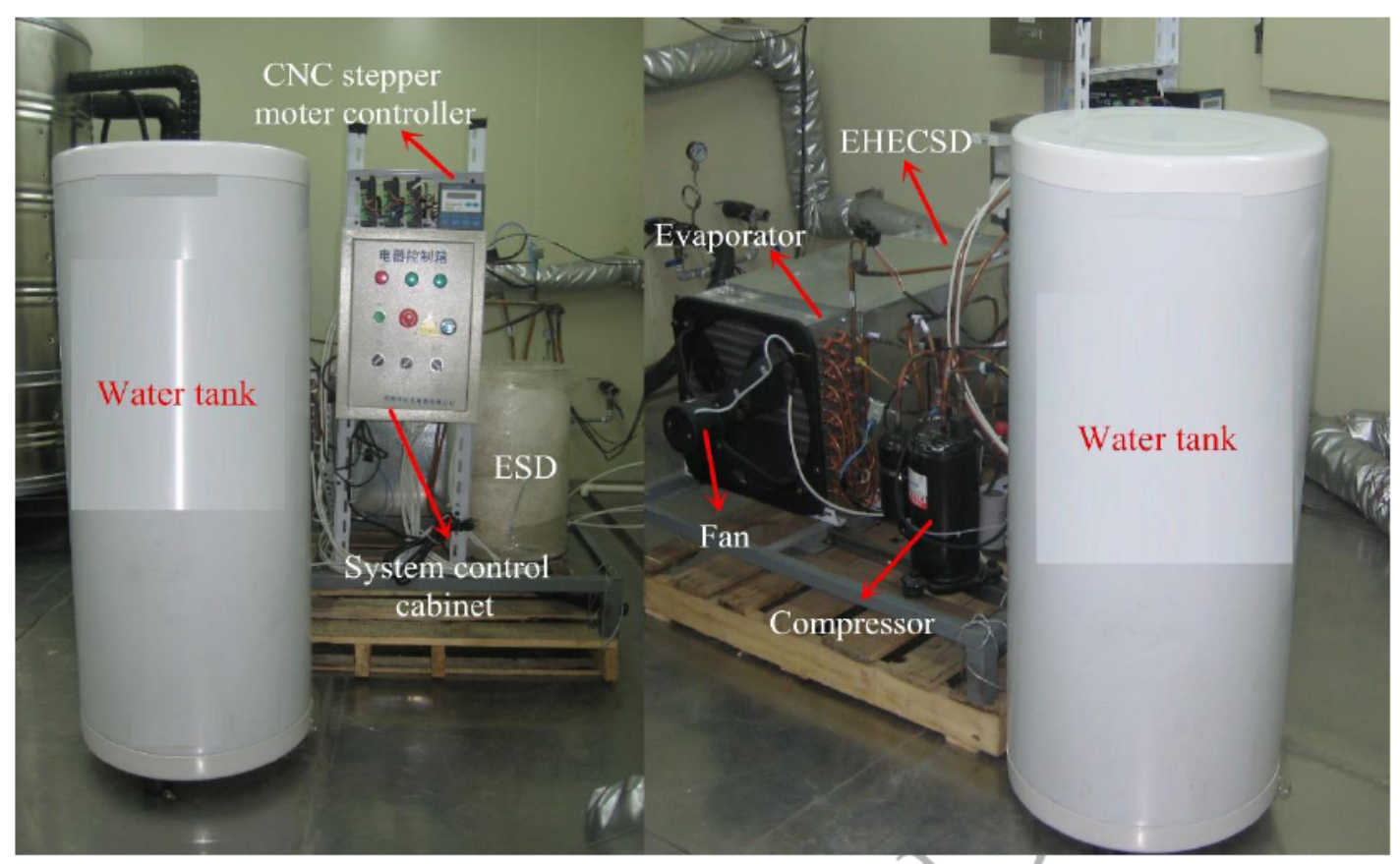

Fig. 2 Photo of the prototype.

Table 1. Detailed parameters of the system

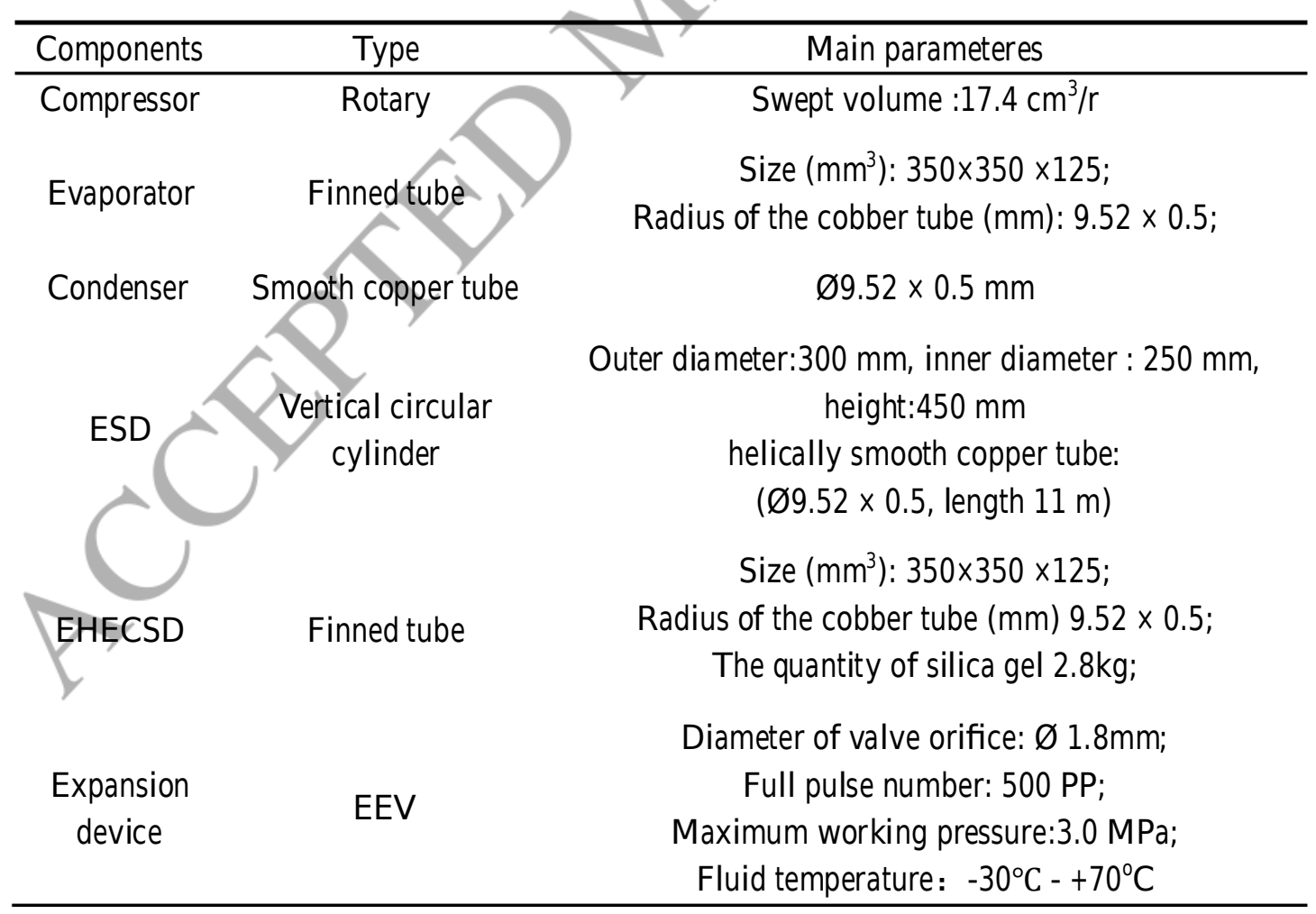




\subsection{Measurement instrumentation}

The layout of the detailed measuring points is showed in Fig. 1. Two pressure transducers with an error less than $\pm 1 \% \mathrm{FS}(6 \mathrm{MPa}$ ) were located at the inlet and outlet lines of the compressor to measure the suction and discharge pressures. T-type thermocouples with an accuracy of $\pm 0.2^{\circ} \mathrm{C}$ were used to measure the temperatures of the refrigerant, water and PCM. The temperature and humidity of the process air after the dehumidification were tested by five temperature and humidity recorders with an accuracy of $\pm 2.0 \%$ located inside the air duct (see Fig. 3). The electrical energy consumption of the compressor and fan were measured by a power meter (i.e. $\pm 0.15 \%$ accuracy). The detailed parameters of the measurement apparatus are shown in Table 2.

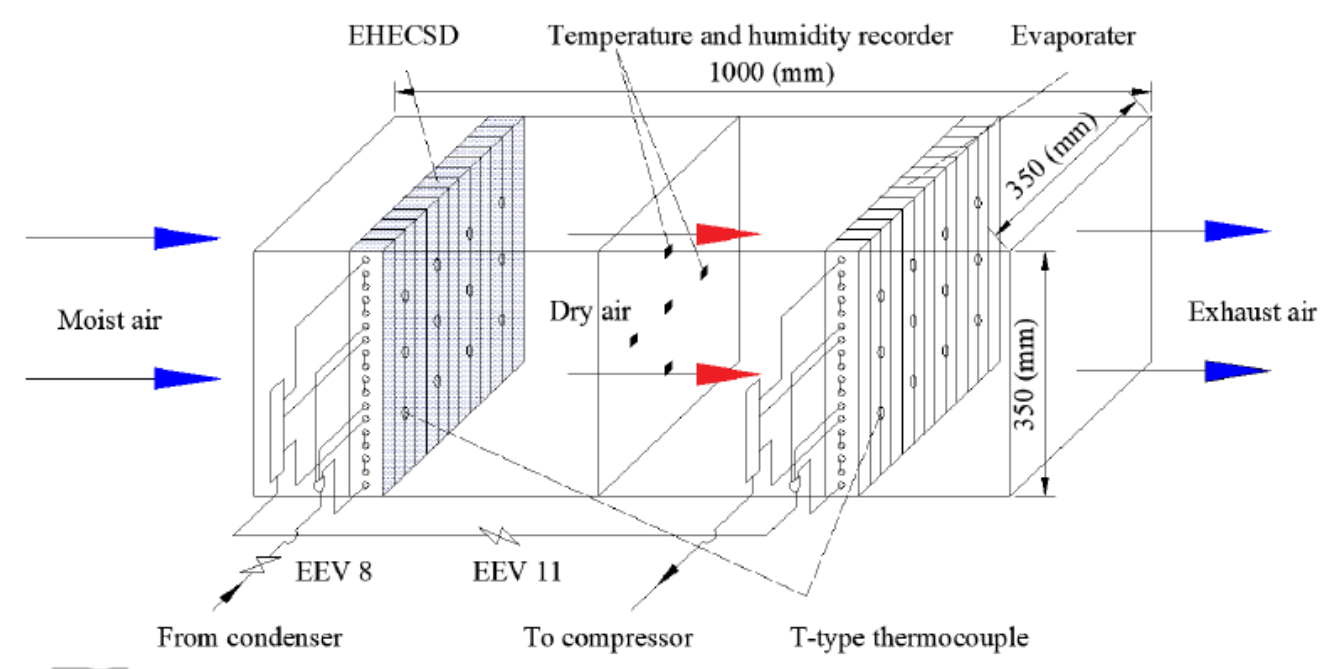

Fig. 3 The layout of the temperature and humidity recorder measurement points. 
Table 2. Detailed characteristics parameters of the measurement apparatus.

\begin{tabular}{|c|c|c|c|}
\hline Measured variable & $\begin{array}{c}\text { Measurement } \\
\text { apparatus }\end{array}$ & Range & Accuracy \\
\hline Temperature $\left({ }^{\circ} \mathrm{C}\right)$ & T-type thermocouple & $-50 \sim 150^{\circ} \mathrm{C}$ & $\pm 0.2^{\circ} \mathrm{C}$ \\
\hline Temperature $\left({ }^{\circ} \mathrm{C}\right)$ & Temperature and & $-20 \sim 70^{\circ} \mathrm{C}$ & \\
\hline Relative humidity (\%) & humidity recorder & $0 \sim 100 \%$ & \\
\hline Pressure (MPa) & pressure transducer & $0 \sim 6$ & \\
\hline Power(kW) & power meter & $0.01 \sim 24.00$ & $1 \%$ of ful \\
\hline
\end{tabular}

\subsection{Experimental conditions and procedure}

In order to study the effect of EEV on the characteristics of the studied system, a set of experiments for various EEV openings were performed. Generally, during the heating mode, as the operation time progressed, the dehumidification performance of the desiccant was decreased due to the moisture increase in the desiccant and absorption heat, resulting in a decrease in the heating capacity of the studied system. Considering this phenomenon, the major subject of analysis was to set the EEV opening of the $1^{\text {st }}$ stage throttle at 65,75 and $85 \%$, and the EEV openings of the $2^{\text {nd }}$ stage throttle at 30,40 and $50 \%$ pulses, respectively. For better control and more flexibility during the testing, the three EEVs used in this experiment prototype were driven by three Computer Numerical Control (CNC) stepper motors using the 1-2 excitation method. Before operating the experiment, R134a was employed for the working fluid and the optimum amount of the refrigerant charge $(1.6 \mathrm{~kg})$ was determined when the system COP is maximum. The dry-bulb temperature and $\mathrm{RH}$ of the environmental chamber were kept at $0{ }^{\circ} \mathrm{C}$ and $85 \%$ respectively. In this condition, the outdoor 
heat exchanger was subjected the most severe frost growth and accumulation, leading to the sharply decrease in the system heating performance.

In this study, three main parameters were employed to evaluate the system performance under different EEV openings of $1^{\text {st }}$ stage throttle and $2^{\text {nd }}$ stage throttle in terms of the dehumidification efficiency and regeneration efficiency as well as COP.

The dehumidification efficiency of the studied system, $\eta_{\text {de }}$, was defined as the ratio of the water vapor mass which was absorbed by the solid desiccant to the water vapor mass which was flowed through the EHECSD during the heating mode, as expressed in Eq. (1).

$$
\eta_{\mathrm{de}}=\frac{m_{\mathrm{hm} \cdot \mathrm{wv}}}{m_{\mathrm{OA} \cdot \mathrm{wv}}}
$$

where $m_{\text {hm owv }}$ is the water vapor mass of the solid desiccant absorbed from the outdoor air , [g]. $m_{\mathrm{OA} \cdot w v}$ is the water vapor mass of the outdoor air flowed through the EHECSD, $[\mathrm{g}]$.

The regeneration efficiency of the studied system, $\eta_{\text {re }}$, was defined as the ratio of the water vapor mass which was removed from the solid desiccant to the total water vapor mass which was absorbed by the solid desiccant during the heating mode and is calculated by Eq. (2).

$$
\eta_{\mathrm{re}}=\frac{m_{\mathrm{rm} \cdot \mathrm{wv}}}{m_{\mathrm{hm} \cdot \mathrm{wv}}}
$$

where $m_{r m \bullet w v}$ is the removed water vapor mass from the solid desiccant during the regeneration mode, $[\mathrm{g}]$.

COP was defined as the ratio of the total heating capacity to the electrical power input during the whole operation including heating mode and regeneration mode, as shown in Eq. (3). 


$$
C O P=\frac{Q}{W}
$$

where $Q$ is the heat capacity from the condenser to the water, $[\mathrm{kW}], W$ was the electrical energy consumption, [kW].

\subsection{Uncertainty analysis}

Each experimental measurement has a certain degree of uncertainty and error due to instrumental, physical and human in adequacies[ 40]. These independent inaccuracies ultimately will result in the uncertainly of the final results. In this work, an uncertainly analysis for the measured variables such as temperature, $\mathrm{RH}$ and power was carried out using the method given by Moffat [41]. The root sum square was used and can be given as Eq. (4).

$$
\delta R=\left\{\sum_{i=0}^{N}\left(\frac{\partial R}{\partial X_{i}} \delta X_{i}\right)^{2}\right\}^{\frac{1}{2}}
$$

where $R$ is a function of the totally $\mathrm{N}$ independent variables $\left(X_{1}, X_{2}, X_{3} \ldots X_{\mathrm{N})}, \delta X_{i}\right.$ is the uncertainty of the independent variable $X_{i}$.

The errors in the measurement of temperature, $\mathrm{RH}$, pressure and electric power were $\pm 0.2(0.5){ }^{\circ} \mathrm{C}, \pm 3 \%, \pm 1 \%$ and $\pm 0.01 \%$, respectively. According to Eq. (4), the total uncertainty associated with the regeneration efficiency $\left(\eta_{\mathrm{re}}\right)$, dehumidification efficiency $\left(\eta_{\mathrm{de}}\right.$, )and COP were $4.13,4.12$ and $4.34 \%$, respectively.

\section{Results and discussions}

In this section, the thermodynamic performance behaviors of the system are presented and discussed based on a set of experiments carried out at the outdoor temperature of $0^{\circ} \mathrm{C}$ and $\mathrm{RH}$ of $85 \%$. The system performance characteristics such as suction and discharge temperatures of the compressor, compression ratio, dehumidification and regeneration efficiency, PCM average temperature, heating capacity and COP were expressed for various 
EEV openings including the $1^{\text {st }}$ stage throttle and $2^{\text {nd }}$ stage throttle. It should be noted that the opening of EEV 17 was kept at 40\% during the regeneration mode in all cases studied.

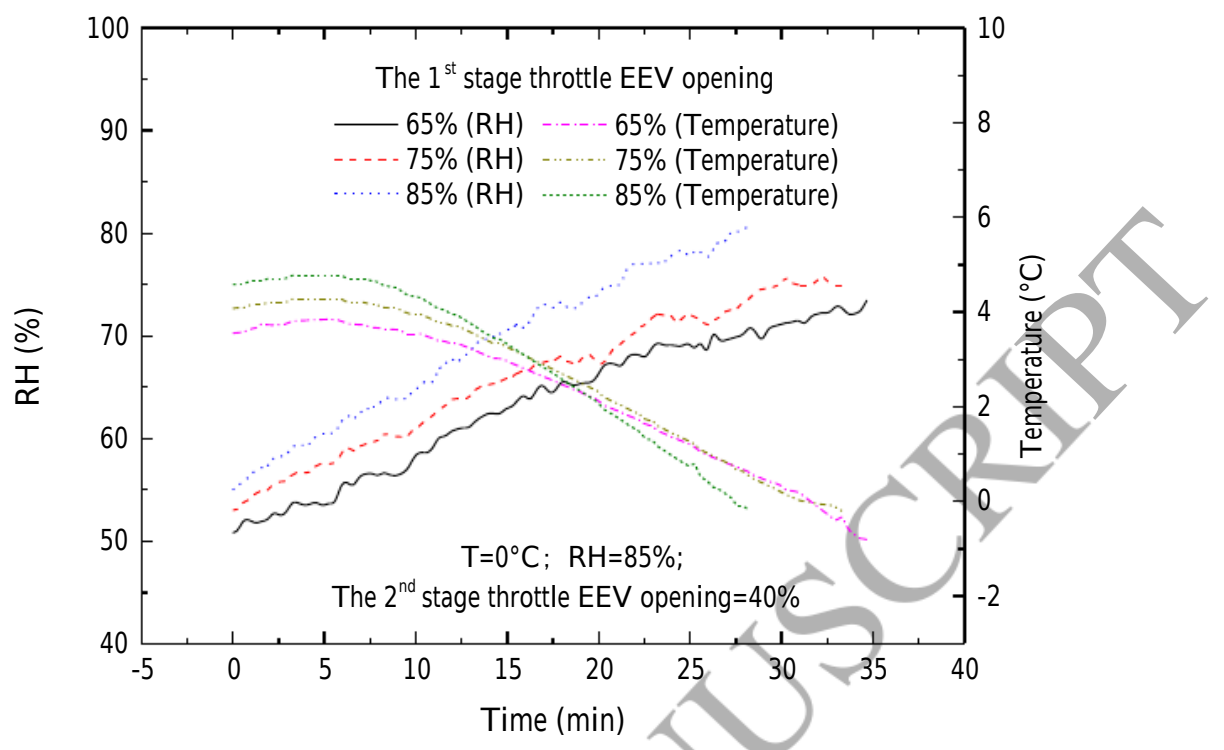

Fig. 4 Measured temperatures and $\mathrm{RH}$ of the process air after dehumidification at the different EEV openings of the $1^{\text {st }}$ stage throttle.

The $1^{\text {st }}$ stage throttle had a significantly influence on the temperature and $\mathrm{RH}$ of the air dehumidified which determined the character of the frost-free operation for the studied system. Fig. 4 depicts the measured profiles of the air outlet temperature and $\mathrm{RH}$ with respect to the EEV opening of the $1^{\text {st }}$ stage throttle ranged from 65 to $85 \%$ at the outdoor temperature of $0^{\circ} \mathrm{C}$ and $\mathrm{RH}$ of $85 \%$ as well as the EEV opening of the $2^{\text {nd }}$ stage throttle of $40 \%$ during the heating mode. From this figure, as the dehumidification process continues, the $\mathrm{RH}$ increased linearly and temperature first slowly decreased and then decreased rapidly with increasing the EEV opening of the $1^{\text {st }}$ stage throttle. For instance, when the EEV opening of the $1^{\text {st }}$ stage throttle was $65 \%$, the relative humidity increased from 50.8 to $73.5 \%$ and the process air temperature decreased from 3.5 to $-0.8^{\circ} \mathrm{C}$. When the EEV opening of the $1^{\text {st }}$ stage throttle 
increased to $85 \%$, the relative humidity increased from $55 \%$ to $80.5 \%$ and the process air temperature decreased from 4.6 to $-0.2^{\circ} \mathrm{C}$. This is due to the fact that at beginning, more empty pores were in the solid desiccant to adsorb air moisture led to higher dehumidification effectiveness. As the moisture in the solid desiccant increase, the dehumidification ability quickly decreased and the generated lower adsorption heat that was caused to the temperature of process air decreased. In addition, the EEV opening of the $1^{\text {st }}$ stage increased caused a higher refrigerant flow gave rise to a higher cooling capacity and a higher temperature difference between the solid desiccant and process air led to a good adsorption as well as decreased sensible heat. This was finally resulted to the decrease in the process air temperature as shown in Fig. 4. It has been also found that the frost-free working times for the system were $34.7,33.2,28.3$ minutes respectively when the EEV opening of the $1^{\text {st }}$ stage throttle was 65,75 and $85 \%$.

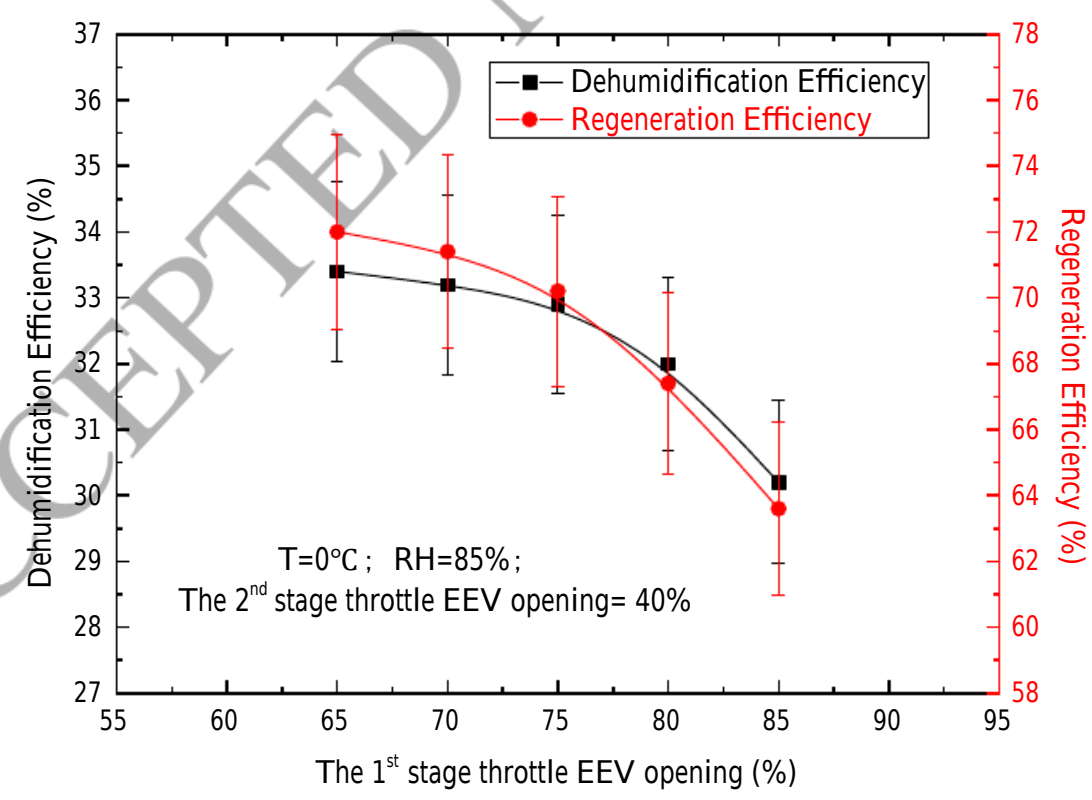

Fig. 5 Variations of the dehumidification efficiency and regeneration efficiency of the studied system at the different EEV openings of $1^{\text {st }}$ stage throttle. 
Fig. 5 evaluated the dehumidification efficiency and regeneration efficiency of the experimental prototype with respect to the EEV opening of the $1^{\text {st }}$ stage throttle ranged from 65 to $85 \%$ at the outdoor temperature of $0^{\circ} \mathrm{C}$ and $\mathrm{RH}$ of $85 \%$ as well as the $2^{\text {nd }}$ stage throttle EEV opening of $40 \%$. It can be observed that the dehumidification efficiency and regeneration efficiency of the system showed a very similar behavior, i.e. increasing in the EEV opening of the $1^{\text {st }}$ stage throttle led to a lower dehumidification efficiency and regeneration efficiency of the studied system, especially when the EEV opening of the 1st-stage throttle increased over 75\%. The dehumidification efficiency decreased from 33.4 to $32.9 \%$ when the EEV opening of the $1^{\text {st }}$ stage throttle increased from 65 to $75 \%$ and decreased from 32.9 to $30.2 \%$ when the EEV opening of the $1^{\text {st }}$ stage throttle increased from 75 to $85 \%$. The reason is that the temperature difference between the solid desiccant and the process air was reduced as the evaporating temperature of EHECSD increased due to the use of a larger EEV opening of the $1^{\text {st }}$ stage throttle, leading to the difference of the vapor partial pressure decrease between of them that resulted in lower diffusion of moisture droplets from process air to the surface of the solid desiccant. Thus, the increasing in the EEV opening of the $1^{\text {st }}$ stage throttle resulted in the decrease in the moisture cycle and decrease in the dehumidification effectiveness of the solid desiccant. It can also be seen that, although the EEV 17 was kept at $40 \%$ during the regeneration mode, the regeneration efficiency decreased when increasing the EEV opening of the $1^{\text {st }}$ stage throttle. The regeneration efficiency decreased from 72 to $70.2 \%$ when the EEV opening of the $1^{\text {st }}$ stage throttle increased from 65 to $75 \%$, while it was decreased from 70.2 to $63.6 \%$ when the $1^{\text {st }}$ stage throttle EEV opening increased from 75 to $85 \%$. This can be attributed to the fact that the frost-free operation time 
decreased as the EEV opening of the $1^{\text {st }}$ stage throttle increased. Due to the same reason presented before, this resulted in a lower storage heat in ESD during the heating mode, and there was not enough energy to heat the solid desiccant in regeneration mode, lead to a decrease of the difference of the vapor partial pressure between the outdoor air and the solid desiccant. Finally, it resulted into decreased removal rate of the moisture from solid desiccant in the regenerative process. It should be noted that although the EEV opening of the $1^{\text {st }}$ stage throttle at $65 \%$ led to a higher dehumidification efficiency and regeneration efficiency, due to the decrease in the refrigerant flow flowed into the evaporator. On the other hand, a large fraction of the refrigerant may be evaporated in EHECSD at the relative small EEV opening of the $1^{\text {st }}$ stage throttle, which led to the refrigerant dryness of the $2^{\text {nd }}$ stage throttle inlet and affected greatly the performance of the $2^{\text {nd }}$ stage throttle. The above two reasons were resulted in the system performance degradation,

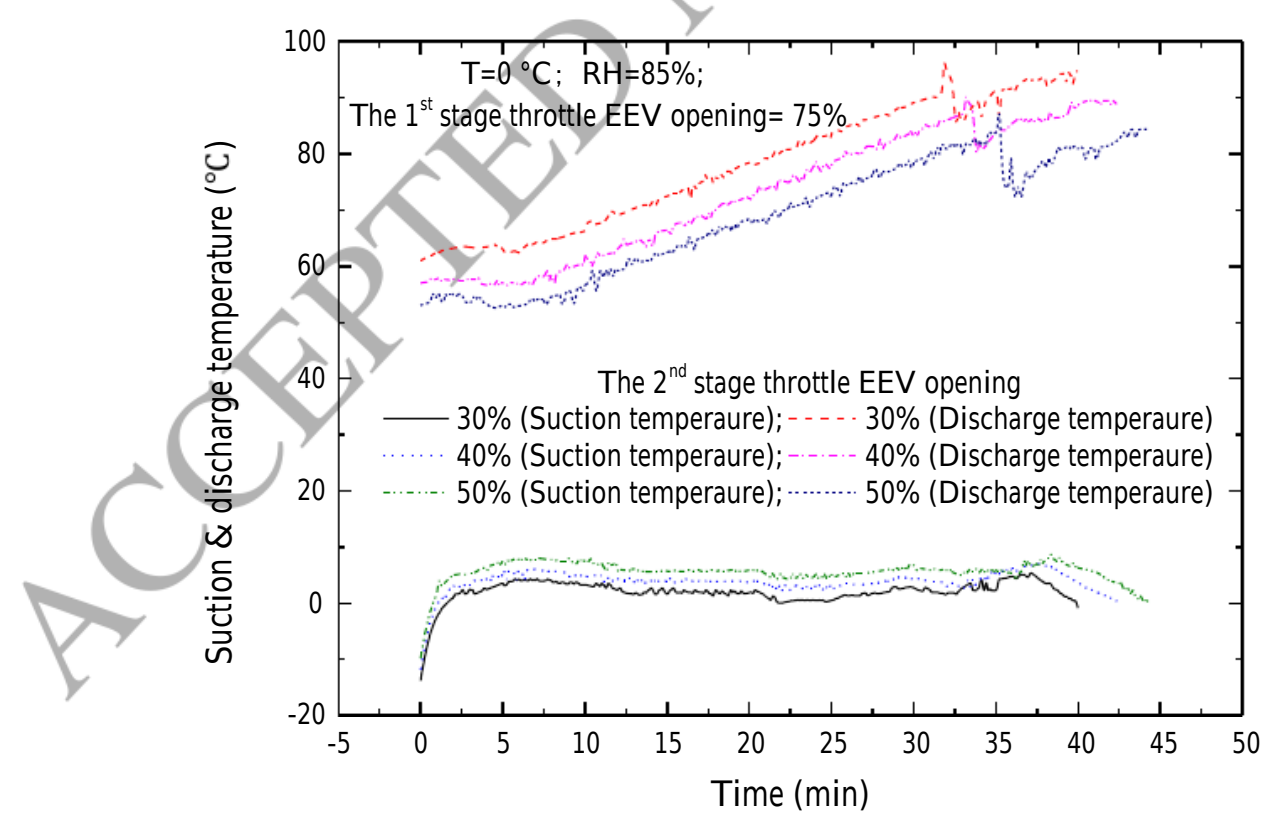

Fig. 6 Measured suction and discharge temperatures of the compressor at the different EEV openings of the $2^{\text {nd }}$ stage throttle. 
Fig. 6 shows the changes of the suction and discharge temperatures of the compressor with respect of time when the EEV opening of the $2^{\text {nd }}$ stage throttle was 30,40 and $50 \%$ at the outdoor temperature of $0^{\circ} \mathrm{C}$ and $\mathrm{RH}$ of $85 \%$ while keeping the EEV opening of the 1st-stage throttle of $75 \%$. It can be seen that the behavior of the suction and discharge temperatures were very similar with different EEV openings of the $2^{\text {nd }}$ stage throttle. The discharge temperature increased quickly with the operation time and the suction temperature experienced a relatively small variation. This was because the temperature difference between the condenser and water decreased gradually with the increase in the water temperature, resulting in the decrease in the heat transfer performance. In addition, the discharge temperature decreased as the EEV opening of the $2^{\text {nd }}$ stage throttle increased. This change trend was in accordance with the change trend presented in Reference [39]. The reason for this phenomenon was that the increasing in the EEV opening leading to the refrigerant flow rate increased, resulted in an increasing of the evaporation temperature. It was clearly seen that the discharge temperature decreased from 94.7 to $84.3^{\circ} \mathrm{C}$ when the EEV opening of the $2^{\text {nd }}$ stage throttle increased from 30 to $50 \%$ at the end of the operation. In the meantime, the average suction temperature increased slightly from 2.1 to5.5 $5^{\circ}$. It should be noted that the discharge temperature decreased sharply at around 31.8, 33.2 and 36.2 minutes when the EEV opening of the $2^{\text {nd }}$ stage throttle was 30,40 and $50 \%$ respectively. This was because the system operation mode was switched from heating to regeneration. Then, with the storage heat decreased in ESD, the discharge temperature increased and suction temperature decreased. It can also be seen that at the three experiment cases, the cycle periods of the system were $40,42.3$ and 44.3 minutes, respectively. 


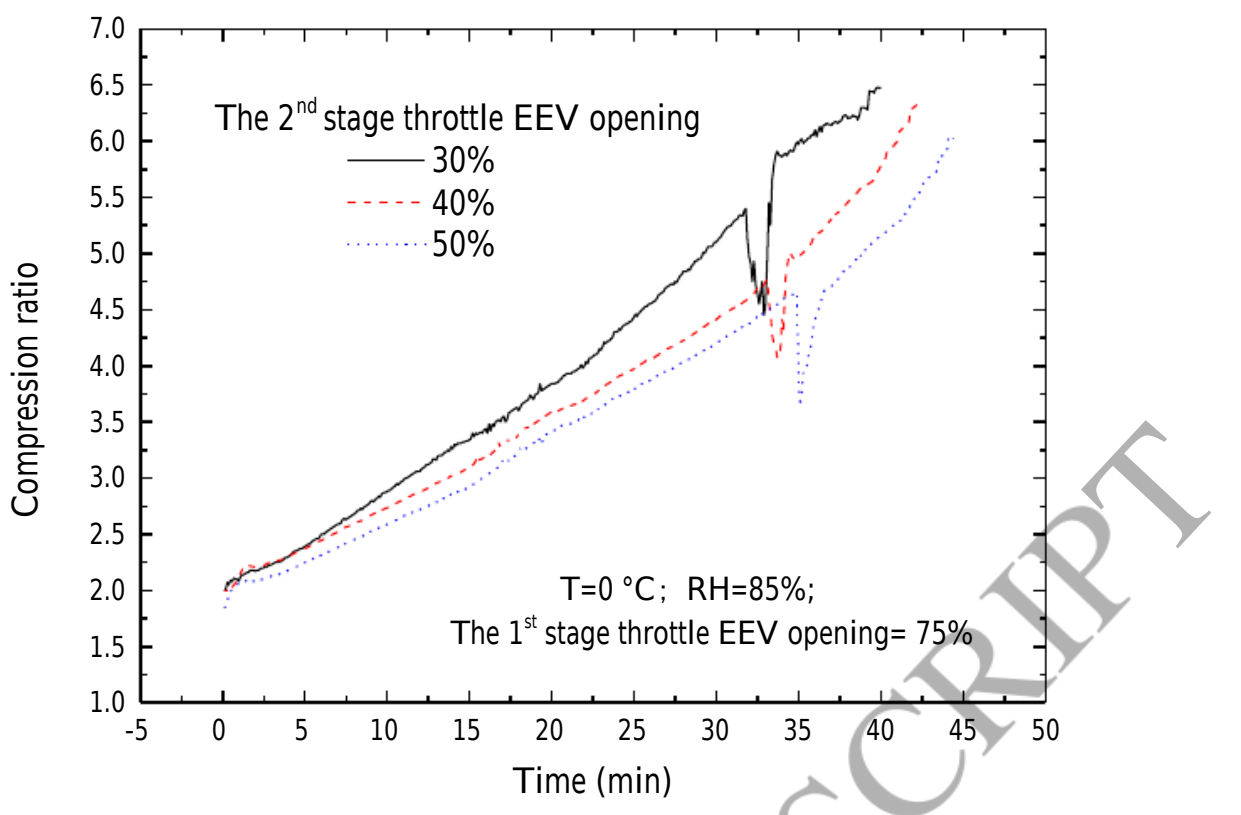

Fig. 7 Measured compressor suction and discharge pressures at the different EEV openings of the $2^{\text {nd }}$ stage throttle.

Fig. 7 shows the variation of the compression ratio with respect to the operation time for three different $2^{\text {nd }}$ stage throttle EEV openings at the outdoor temperature of $0^{\circ} \mathrm{C}$ and $\mathrm{RH}$ of $85 \%$ and the EEV opening of the $1^{\text {st }}$ stage throttle of $75 \%$. It can be found that, during the heating mode, the variations of the compressor ratio followed a nearly straight linear function of the heating time. This can be explained that as the water temperature increased gradually, the temperature between the condenser and water decreased, which led to the discharge pressure increased, although the suction pressure was nearly unchanged. It can also be found that the compressor ratio first decreased sharply and then increased gradually when the operation mode was switched to the regeneration. This was because the heat stored in ESD was acted as the low heat source and enhanced the suction pressure and decreased the discharge pressure. As the heat stored in ESD decreased, the compressor ratio increased gradually. When the EEV opening of the $2^{\text {nd }}$ stage throttle was $40 \%$, for instance, the 
compressor ratio was 2 at the beginning of the operation and increased to 4.6 at the end of the heating mode. When the operation mode was switched to the regeneration, the compressor ratio first decreased to 4.1 and then increased to 6.3 .

It can also be seen that the compressor ratio decreased with the increase of the EEV opening of the $2^{\text {nd }}$ stage throttle. At the end of the heating mode, the compressor ratios were 5.4, 4.6 and 4.5 when the EEV opening of the $2^{\text {nd }}$ stage throttle was 30,40 and $50 \%$, respectively. It can be explained by the fact that with the increase in the EEV opening of the $2^{\text {nd }}$ stage throttle, lead to the increase in the refrigerant flow rate, resulting in the discharge pressure decreased. However, the suction pressure almost unchanged as the test condition in the evaporating side remained constant. Thus, the system compressor ratio dropped.

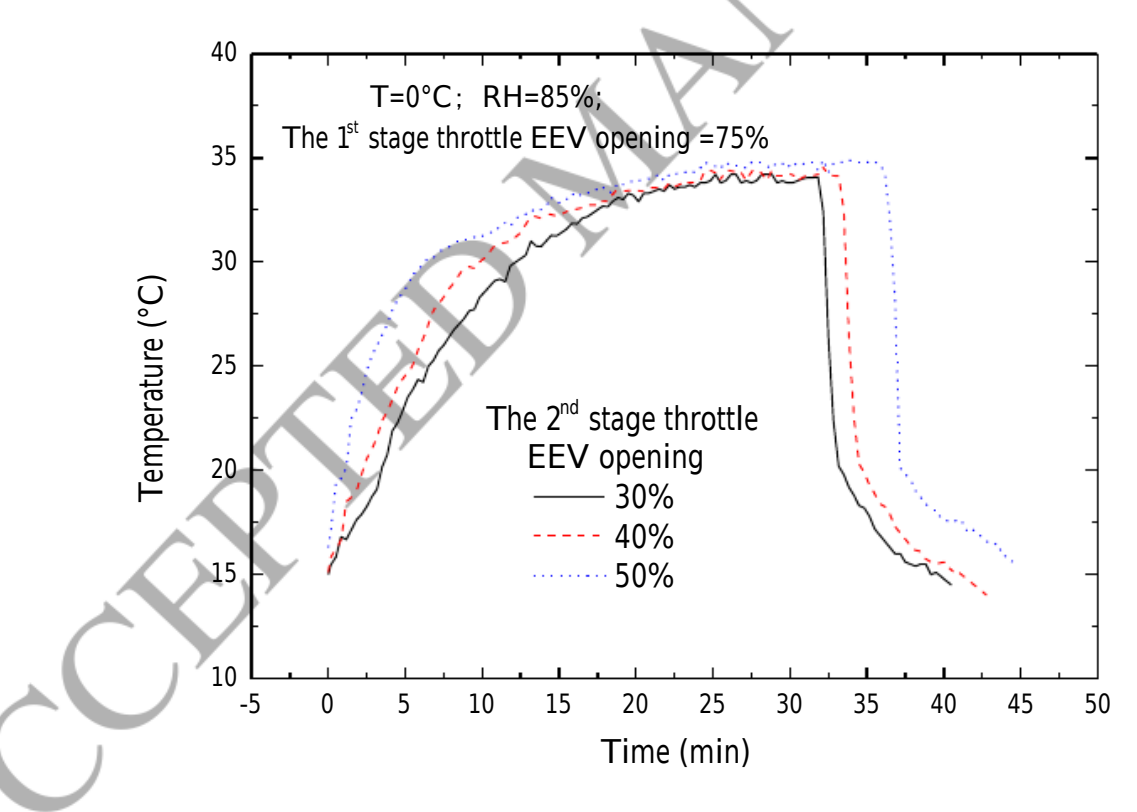

Fig. 8 Measured PCM temperature at the different EEV openings of the $2^{\text {nd }}$ stage throttle.

Fig. 8 presents the changes of the PCM temperature with respect to the operation time for three different $2^{\text {nd }}$ stage throttle EEV openings at the outdoor temperature of $0^{\circ} \mathrm{C}$ and $\mathrm{RH}$ of $85 \%$ and the EEV opening of the $1^{\text {st }}$ stage throttle of $75 \%$. It is clearly seen that the PCM 
temperature increased quickly to around $30^{\circ} \mathrm{C}$ after the system operated for 6 minutes when the EEV opening of the $2^{\text {nd }}$ stage throttlewas $50 \%$. At the same time, it was $3.5^{\circ} \mathrm{C}$ and $5.6^{\circ} \mathrm{C}$ higher than that of 30 and $40 \%$, respectively. An explanation for this could be that the increasing in the EEV opening resulted in the refrigerant flow rate increased, resulting in the quick increase in the PCM temperature and therefore more heat capacity was stored to the ESD. Once the temperature reached to the PCM phase change temperature resulting in the PCM temperature changed gradually flattened. When the operation mode was switched to the regeneration, the PCM temperature dropped quickly due to the ESD was acted as a heat source.

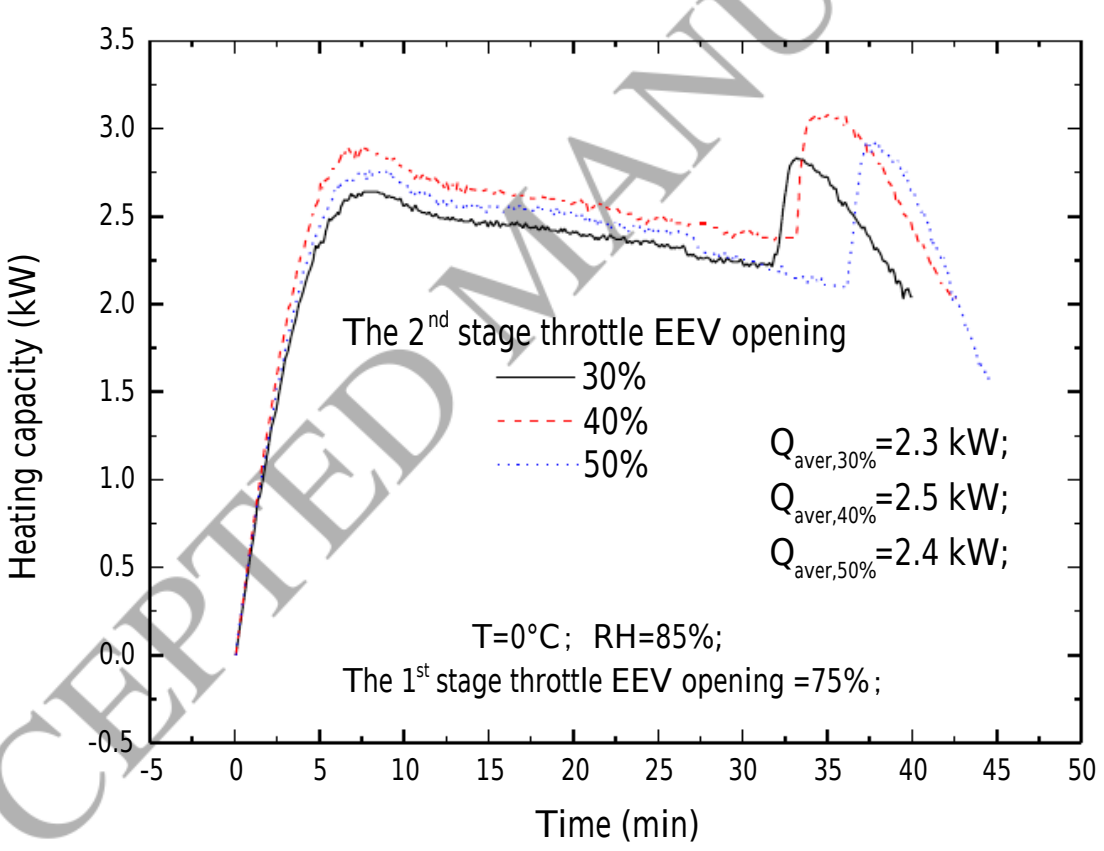

Fig. 9 The heating capacity of the experimental prototype at the different EEV openings of the $2^{\text {nd }}$ stage throttle.

The variations of the system heating capacity with respect to the operation time for the EEV opening of the $2^{\text {nd }}$ stage throttle of 30,40 and $50 \%$ at the outdoor temperature of $0^{\circ} \mathrm{C}$ and $\mathrm{RH}$ of $85 \%$ and the EEV opening of the $1^{\text {st }}$ stage throttle of $70 \%$ is illustrated in Fig. 9. 
The heating capacity of the experimental prototype obviously increased and then slightly decreased with the operation time in the heating mode. When the operation mode was switched to the regeneration, it increased suddenly and then decreased sharply. The reason for this phenomenon is that the refrigerant flow rate increased as the EEV opening of the $2^{\text {nd }}$ stage throttle increased. However, the opening of EEV was too wide, and the enthalpy difference across the condenser was decreased, leading to the decrease in the performance of throttle. Therefore, when the EEV opening of the $2^{\text {nd }}$ stage throttle was $40 \%$, the average heating capacity of the experimental prototype was $2.5 \mathrm{~kW}$, that was 0.2 and $0.1 \mathrm{~kW}$ higher than that when the EEV opening of the $2^{\text {nd }}$ stage throttle was 30 and $50 \%$, respectively. Similar findings were also reported by Hou et al. [39] and Baek [42]. In addition, a large fraction of the refrigerant was entered into the evaporator and part of them was not evaporated completely if the $2^{\text {nd }}$ stage throttle of the EEV opened too wide, leading to the decrease in the heating capacity. A small amount of liquor with the refrigerant vapor flowed into the compressor and this will have a great influence on the performance of the compressor. Therefore, the $2^{\text {nd }}$ stage throttle should be kept at the opening of $40 \%$ to ensure an optimal performance of the studied system. 


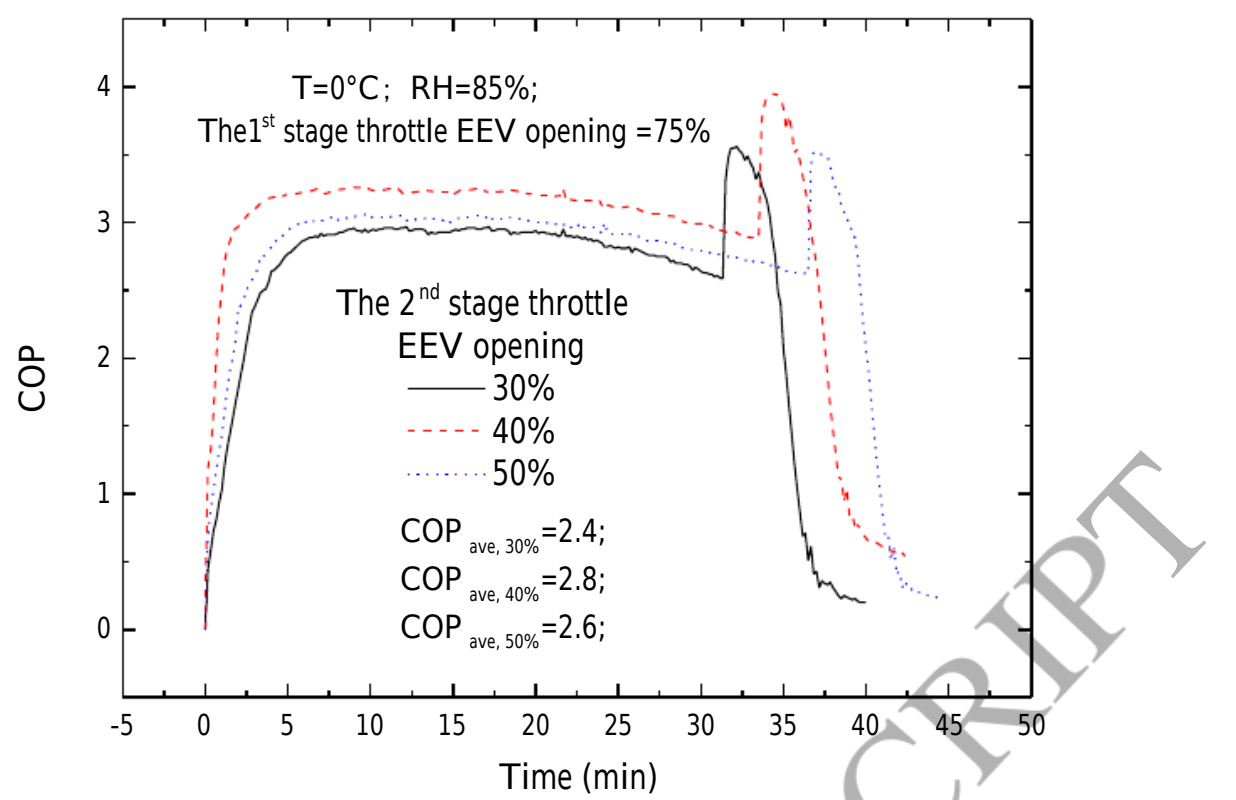

Fig. 10 Illustration of the COP of the experimental prototype at the different EEV openings of the $2^{\text {nd }}$ stage throttle.

Fig. 10 illustrates the COP of the experimental prototype under the different EEV openings of the $2^{\text {nd }}$ stage throttle. It is obvious that the COP of the experimental prototype increased quickly at the earlier stage of around 6 minutes, and then descended gradually from 6 minutes to the end of the heating mode. This was due to the fact that the compression ratio and irreversibility increased as the increase of the water temperature. Also can be seen that the system COP increased sharply at first and then decreased steeply when the operation mode was switched to the regeneration. The reason for this phenomenon is that a higher heat source caused a higher evaporating temperate, which led to the system heating capacity increased and the compressor power consumption decreased. According to Eq. (3), the system performance will be improved. As the heat source temperature dropped, the system heating capacity was decreased and the compressor power consumption was increased, resulting that the system performance deteriorated sharply. Compared with the three cases, the maximum 
average COP of the experimental prototype was 2.8 when the EEV opening of the $2^{\text {nd }}$ stage throttle was $40 \%$ that was 0.4 and 0.2 higher than that when the EEV opening of the $2^{\text {nd }}$ stage throttle of 30 and $50 \%$, respectively. This was because, at a narrow opening, the degree of superheat of the system was very high and the evaporator area was inefficiently utilized, leading to the heating capacity and COP of the system decreased. The system refrigerant flow increased as the EEV opening of the $2^{\text {nd }}$ stage throttle increased. It raised the evaporating temperature and more condensation waste heat was absorbed by ESD in the heating mode. This further increased the regeneration temperature and hence more moisture removed from the solid desiccant. Thus, the system COP was improved. The reason for causing a lower COP at the EEV opening of the $2^{\text {nd }}$ stage throttle of $50 \%$ was that although it increased the refrigerant flow rate in the studied system, it caused the EEV throttle shocked and deviated from the optimal work condition. In addition, the increase in the refrigerant flow rate induced an increase in the compressor power consumption, which eventually led to the performance degradation of the studied system. This illustrated that the EEV opening of the $2^{\text {nd }}$ stage throttle had a significant impact on the COP of the experimental prototype.

Table 3. The average COP at different EEV openings of the $1^{\text {st }}$ stage and $2^{\text {nd }}$ stage throttle

\begin{tabular}{cccccc}
\hline \multirow{2}{*}{\begin{tabular}{c} 
The $2^{\text {nd }} \begin{array}{l}\text { The } \\
\text { EEV opening (\%) }\end{array}$ \\
\cline { 2 - 6 }
\end{tabular}} & \multicolumn{5}{c}{ st stage throttle EEV opening (\%) } \\
\cline { 2 - 6 } & 30 & 35 & 40 & 45 & 50 \\
\hline 65 & 2.41 & 2.48 & 2.57 & 2.5 & 2.46 \\
70 & 2.42 & 2.58 & 2.78 & 2.63 & 2.52 \\
75 & 2.44 & 2.58 & 2.83 & 2.67 & 2.58 \\
80 & 2.43 & 2.54 & 2.76 & 2.61 & 2.53 \\
85 & 2.4 & 2.51 & 2.71 & 2.66 & 2.49 \\
\hline
\end{tabular}




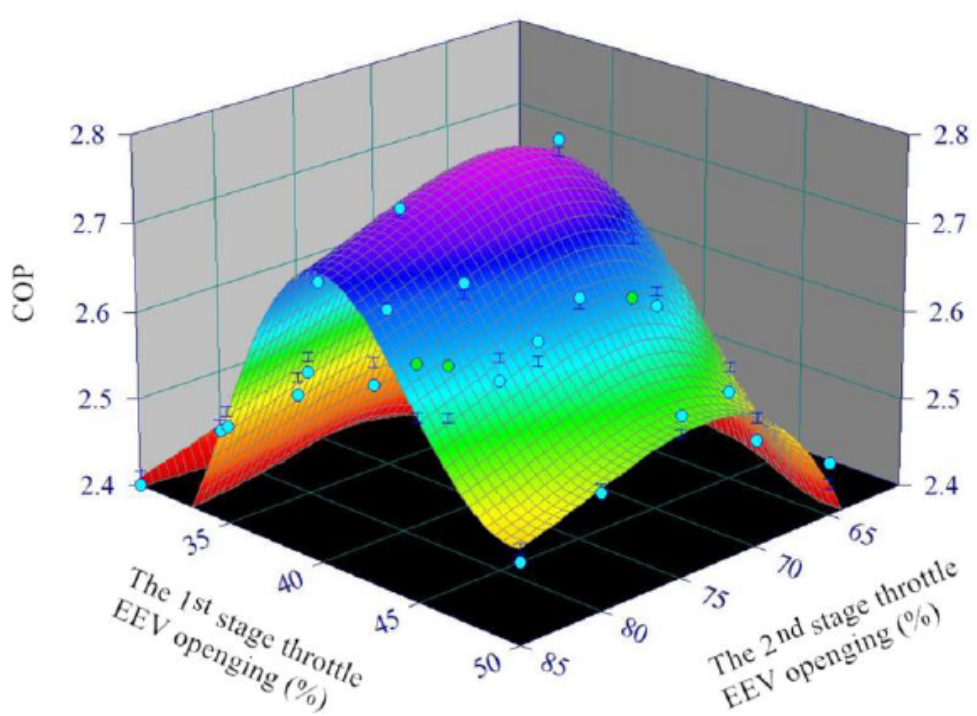

Fig. 11 The average COP of the experimental prototype at different EEV openings of the $1^{\text {st }}$

$$
\begin{aligned}
& \text { stage throttle and 2nd-stage throttle. } \\
& C O P^{-1}=\mathrm{a}+\frac{\mathrm{b}}{V_{1}}+\frac{\mathrm{c}}{V_{1}^{1.5}}+\frac{\mathrm{d} \ln V_{1}}{V_{1}^{2}}+e \ln V_{2}+\frac{\mathrm{f}}{\ln V_{2}}+\frac{g}{V_{2}}+\frac{h}{V_{2}^{1.5}}
\end{aligned}
$$

where $V_{1}$ and $V_{2}$ represent the EEV openings of the $1^{\text {st }}$ stage throttle and $2^{\text {nd }}$ stage throttle, respectively. The coefficients of $a, b, c, d, e, f, g$ and $h$ were 8690.2, 4852.7, -89409.7, 104434.0, -758.6, -26444.3, 57621.6 and-43143.1, respectively.

Table 3 shows the changes of the average COP of the experimental prototype at different EEV openings of the $1^{\text {st }}$ stage throttle and $2^{\text {nd }}$ stage throttle when the outdoor temperature was $0^{\circ} \mathrm{C}$ and $\mathrm{RH}$ was $85 \%$. It can be seen that from this figure, the system average COP was relative higher when the EEV opening of the $2^{\text {nd }}$ stage throttle was $40 \%$ than the other experimental cases. The maximum system average COP was 2.83 when the EEV opening of the $1^{\text {st }}$ stage throttle was $75 \%$ and the EEV opening of the $2^{\text {nd }}$ stage throttle was $40 \%$. The maximum average COP was 2.57 when the EEV opening of the $1^{\text {st }}$ stage was $65 \%$ and the EEV opening of the $2^{\text {nd }}$ stage throttle increased. This was because the low refrigerant flowed 
into the evaporator, leading to a lower heating capacity. At the EEV opening of the ${ }^{\text {st }}$ stage throttle of $75 \%$, the increase or decrease in the EEV opening of the $2^{\text {nd }}$ stage throttle cannot enable the system COP to be optimized when the EEV opening of the $2^{\text {nd }}$ stage throttle was deviated from $40 \%$. This was illustrated that the EEV openings of the $1^{\text {st }}$ stage and $2^{\text {nd }}$ stage throttle had a great influence on the system COP. In order to analyze the sensitivity of the EEV openings of the $1^{\text {st }}$ stage and $2^{\text {nd }}$ stage throttle on the system average COP, a correlation (Eq. 5) and a three-dimension curved surface (Fig. 11) of the average COP with the EEV opening of the $1^{\text {st }}$ stage and $2^{\text {nd }}$ stage throttle were obtained through the regression analysis of the experimental data. It can also be seen from Fig.11 and Table 3, to obtain the optimal system performance, the EEV openings of the $1^{\text {st }}$ stage and $2^{\text {nd }}$ stage throttle should be kept at $75 \%$ and $40 \%$ respectively.

\section{Conclusions}

This study reported an experimental investigation on the effect of the EEV openings of the $1^{\text {st }}$ stage (from 65 to $85 \%$ ) throttle and $2^{\text {nd }}$ stage (from 30 to $50 \%$ ) throttle on the performance of a novel frost-free ASHP system integrated with solid dehumidification and PCMs at the outdoor temperature of $0^{\circ} \mathrm{C}$ and $\mathrm{RH}$ of $85 \%$. The key findings of this work are as follows.

(1) It was found that the increase in the EEV opening of the $1^{\text {st }}$ stage throttle led to a lower dehumidification efficiency and a lower regeneration efficiency of EHECSD when the EEV opening of the $1^{\text {st }}$ stage throttle increased over $75 \%$.

(2) The discharge temperature of the compressor and compressor ratio decreased while the suction temperature of the compressor experience a relatively small variation when 
increasing the opening of the $2^{\text {nd }}$ stage throttle at the optimal opening of the 1st-stage throttle.

(3) Compared with the three cases, the maximum average COP of the experimental prototype was 2.8 when the EEV opening of the $2^{\text {nd }}$ stage throttle was $40 \%$ that was 0.4 and 0.2 higher than that when the EEV opening of the $2^{\text {nd }}$ stage throttle of 30 and $50 \%$, respectively.

In conclusion, the EEV openings of the $1^{\text {st }}$ stage throttle and $2^{\text {nd }}$ stage throttle had a significant effect on the COP of the experimental prototype. It was advised that the EEV opening of the $1^{\text {st }}$ stage throttle and $2^{\text {nd }}$ stage throttle should be maintained at around $75 \%$ and $40 \%$ respectively in order to achieve an optimum system performance.

\section{Acknowledgements}

The work was supported by National Natural Science Foundation of China (No. 51606139), China Postdoctoral Science Foundation Funded Projects (No. 2016 M590950 and No. 2017T100753) and Shaanxi Province Postdoctoral Science Foundation Funded Projects (No. 2017BSHTDZZ17)

\section{References}

[1]H. Li, Y. Sun, Operational performance study on a photovoltaic loop heat pipe/solar assisted heat pump water heating system. Energ. Buildings, 158 (2018)861-872.

[2]R. Yao, B. Li, K. Steemers, Energy policy and standard for built environment in China. Renew. Energy 30 (2005)1973-1988.

[3]C. Yong, W. Yiping, Z. Li, Performance analysis on a building-integrated solar heating and cooling panel. Renew. Energy 74 (2015) 627-632.

[4]A. Amirirad, R. Kumar, A.S. Fung, Experimental and simulation studies on air source heat 
pump water heater for year-round applications in Canada. Energ. Buildings. 165 (2018)141-149.

[5]M. Song, C.Tso, C.Y. Chao, Techno-economic analysis on frosting/defrosting operations for an air source heat pump unit with an optimized multi-circuit outdoor coil. Energ. Buildings. 166 (2017)165-177.

[6]W.Wang, Q.C.Guo, Y.C.Feng, et al. Theoretical study on the critical heat and mass transfer characteristics of a frosting tube. Appl. Therm. Eng. 54 (2013), 153-160.

[7]L. Zhang, J. Dong, Y. Jiang, et al., An experimental study on frosting and defrosting. Energ. Buildings. 163 (2018), 10-21.

[8]H. Willem, Y. Lin, A. Lekov, Review of energy efficiency and system performance of residential heat pump water heaters. Energ. Buildings. 143 (2017)191- 201.

[9]P.L.T.Brian, R.C.Reid, Y.T.Shah, Frost deposition on cold surfaces. Ind. Eng. Chem. Fundamen. 9 (1970) 375-380.

[10] M.L. Qu, L. Xia, S.M. Deng, Y.Q. Jiang. Improved indoor thermal comfort during defrost with a novel reverse-cycle defrosting method for air source heat pumps. Build. Environ. 45 (2010) 2354-2361.

[11]M.J.Song, S.M.Deng, N.Mao,et al., An experimental study on defrosting performance for an air source heat pump unit with a horizontally installed multi-circuit outdoor coil. Appl. Energy 165 (2016a) 371-382.

[12]M. Song, K. Wang, S. Liu, Techno-economic analysis on frosting and defrosting operations of an air source heat pump unit applied in a typical cold city. Energ. Buildings, 162(2018)65-76. 
[13] J. Dong, S. Deng, Y. Jiang, et al., An experimental study on defrosting heat supplies and energy consumptions during a reverse cycle defrost operation for an air source heat pump, Appl. Therm. Eng. 37 (2012) 380-387.

[14] M.L. Qu, L. Xia, S.M. Deng, Y.Q. Jiang, A study of the reverse cycle defrosting performance on a multi-circuit outdoor coil unit in an air source heat pump -Experiments, Appl. Energy, 91 (2012) :122-129

[15]M.J. Song, L. Xia, N. Mao, An experimental study on even frosting performance of an air source heat pump unit with a multi-circuit outdoor coil. Appl. Energy,164 (2016) 36-44

[16]N.K. Anand, J.S. Schliesing, D.L. O’Neal, et al., Effects of outdoor coil fan prestart on pressure transients during the reverse cycle defrost of a heat pump. ASHRAE Trans. 95(1989)699-704.

[17]W.A. Miller, Laboratory examination and seasonal analysis of frosting and defrosting for an air-to-air heat pump. ASHRAE Trans. 93(1987)1447-89.

[18] M.L. Qu, T. Li, S.M. Deng, Improving defrosting performance of cascade air source heat pump using thermal energy storage based reverse cycle defrosting method. Appl. Therm. Eng. 2017 (2017) 728-736

[19] B. Hu, D. Yang, F. Cao, et al., Hot gas defrosting method for air-source transcritical CO2 heat pump systems. Energ. Buildings, 86 (2015) 864-872.

[20] J. Dong, S. Li, Y. Yao, et al., Defrosting performances of a multi-split air source heat pump with phase change thermal storage, Int. J. Refrig. 55 (2015) 49-59.

[21] L. Cai, R. Wang, P. Hou, et al. Study on restraining frost growth at initial stage by hydrophobic coating and hygroscopic coating. Energ. Buildings. 43 (2011) 1159-1163. 
[22] H.Y. Ye, J.S. Park,K.S. Lee,Frost retardation on fin-tube heat exchangers using mass transfer characteristics with respect to air velocity. Int. J. Heat Mass Transfer, 79 (2014) 689-693.

[23] F. Wang, C.H. Liang, M.T. Yang, et al., Preliminary study of a novel defrosting method for air source heat pumps based on superhydrophobic fin, Appl. Therm. Eng. 90 (2015) 136-144.

[24] D. Huang, Q. Li, X. Yuan, Comparison between hot-gas bypass defrosting and reverse-cycle defrosting methods on an air-to-water heat pump. Appl. Energy 86(2009)1697-703

[25] J. Kim, H.J. Choi, K.C. Kim. A combined dual hot-gas bypass defrosting method with accumulator heater for an air-to-air heat pump in cold region. Appl. Energy 147 (2015) $344-52$.

[26] W. Wang, J. Xiao, Q.C. Guo, Field test investigation of the characteristics for the air source heat pump under two typical mal-defrost phenomena. Appl. Energy 88 (2011), $4470-4480$.

[27] J. Liu, Y. Sun, W. Wang. Performance evaluation of air source heat pump under unnecessary defrosting phenomena for nine typical cities in China. Int. J. Refrig.74(2016) $385-398$

[28] J.H. Zhu, Y.Y. Sun, W. Wang, et al. A novel temperature-humidity-time defrosting control method based on a frosting map for air-source heat pumps Int. J. Refrig. 54 (2015)45-54

[29] Y.J. Ge, Y.Y. Sun, W. Wang, et al. Field test study of a novel defrosting control method for air-source heat pumps by applying tube encircled photoelectric sensors. Int. J. Refrig. 
66 (2016) 133-144.

[30] W. Wang, J. Xiao, Q.C. Guo, et al. Field test investigation of the characteristics for the air source heat pump under two typical mal-defrost phenomena. Appl. Energy, 88 (2011) 4470-4480

[31] Y. Li, G. Chen, L. Tang, et al. Analysis on performance of a novel frost-free air-source heat pump system. Fuel Energy Abstr., 46 (2011)2052-2059

[32] W. Su, X. Zhang, Performance analysis of a novel frost-free air-source heat pump with integrated membrane-based liquid desiccant dehumidification and humidification. Energ. Buildings, 145 (2017) 293-303.

[33] Y. Jiang, H. Fu, Y. Yao, et al., Experimental study on concentration change of spray solution used for a novel non-frosting air source heat pump system. Energ. Buildings, 68 (2014)707-712.

[34] L. Zhang, M. Saikawa, Combination of air-source heat pumps with liquid desiccant dehumidification of air, Energy Convers. Manage. 57 (2011) 107- 116.

[35] L. Zhang, M. Saikawa, A new method for preventing air-source heat pump water heaters from frosting, Int. J. Refrig. 35 (2012) 1327-1334.

[36] F. Wang, Z. Wang, Y. Zheng, et al., Performance investigation of a novel frost-free air-source heat pump water heater combined with energy storage and dehumidification, Appl. Energy 139 (2015) 212-219.

[37] Z. Wang, Y. Zheng, F. Wang, et al., Experimental analysis on a novel frost-free air source heat pump water heater system. Appl. Therm. Eng. 70 (2014) 808-816.

[38] J.W. Peng, H. Li, C.L. Zhang, Performance comparison of air-source heat pump water 
heater with different expansion devices. Appl. Therm. Eng. 99(2016) 1190-1200.

[39] Y. Hou, J. Ma, C. Liu, Experimental investigation on the influence of EEV opening on the performance of transcritical CO2 refrigeration system. Appl. Therm. Eng.65 (2014)51-56

[40] J.P. Holman, Experimental Methods for Engineers. McGraw Hill, New York (2012).

[41] R.J. Moffat, Describing the uncertainties in experimental results. Exp. Therm. Fluid Sci. 1 (1988) 3-17.

[42] C. Baek, J. Heo, J. Jung, Optimal control of the gas-cooler pressure of/a CO 2 heat pump using EEV opening and outdoor fan speed in the cooling mode. Int. J. Refrig.36 (2013) 1276-1284. 


\section{Figure captions}

Fig. 1 Schematic diagram of the novel frost-free ASHPWH system.

Fig. 2 Photo of the prototype.

Fig. 3 The layout of the temperature and humidity recorder measurement points.

Fig. 4 Measured temperatures and RH of the process air after dehumidification at the different EEV openings of the $1^{\text {st }}$ stage throttle.

Fig. 5 Variations of the dehumidification efficiency and regeneration efficiency of the studied system at the different EEV openings of $1^{\text {st }}$ stage throttle.

Fig. 6 Measured suction and discharge temperatures of the compressor at the different EEV openings of the $2^{\text {nd }}$ stage throttle.

Fig. 7 Measured compressor suction and discharge pressures at the different EEV openings of the $2^{\text {nd }}$ stage throttle.

Fig. 8 Measured PCM temperature at the different EEV openings of the $2^{\text {nd }}$ stage throttle.

Fig. 9 The heating capacity of the experimental prototype at the different EEV openings of the $2^{\text {nd }}$ stage throttle.

Fig. 10 Illustration of the COP of the experimental prototype at the different EEV openings of the $2^{\text {nd }}$ stage throttle.

Fig. 11 The average COP of the experimental prototype at different EEV openings of the $1^{\text {st }}$ stage throttle and 2nd-stage throttle. 